\title{
Study on the Change of Sales and Influence of Tsingtao Beer during Epidemic
}

\author{
Haoyue Jiang ${ }^{1, *}$ \\ ${ }^{1}$ Business College, Xi'an University of Finance and Economics, Xi'an, Shaanxi province, China, 710100
${ }^{*}$ Corresponding author. Email: 1617860374@qq.com
}

\begin{abstract}
Tsingtao Beer was set in 1903 as one of the most famous and biggest beer brands in China. However, in 2020, Yang believes that the coronavirus and the quarantine policies limited tourism and also have an impact on the sale of the Tsingtao Beer [1].

This paper mainly illustrates the Sale volume changes during the epidemic and the further development of Tsingtao Beer after the post epidemic era based on the SWOT and PEST analysis. Besides, this paper will study the sale and business strategies of Tsingtao Beer. Based on the analysis, this paper will point out the defects and advantages of the Tsingtao Beer and find out the solutions.
\end{abstract}

Keywords: Tsingtao Beer, Coronavirus disease, Tsingtao Beer International Festival, Tourism

\section{INTRODUCTION}

In the previous paper, it is believed that the coronavirus disease has a negative impact on the tourism and further has influence on the sales of Tsingtao Beer [1]. This paper will use SWOT and PEST to analyzes Tsingtao Beer. And also provide some possible solutions to the Tsingtao Beer for their future development.
As in Figure 1, because of the new business strategies they exerted, Tsingtao Beer performed well in the 2020's sales. When the first quarter of the sales volume decreased, they changed the sales strategy swiftly. With profits falling 20 percent in First quarter contrast with 2019, sales exceeded the second quarter comparing with 2019. Figure 2 shows operating income in 2020 just slightly lower than in 2019.

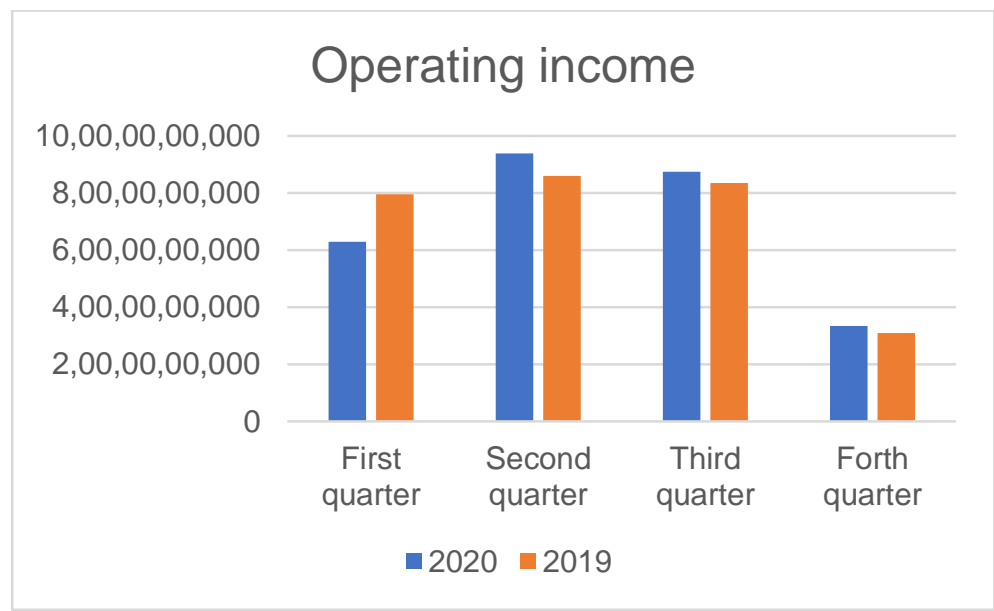

Figure 1 Comparing the operating income between 2019 and 2020[2] 


\section{Operating income}

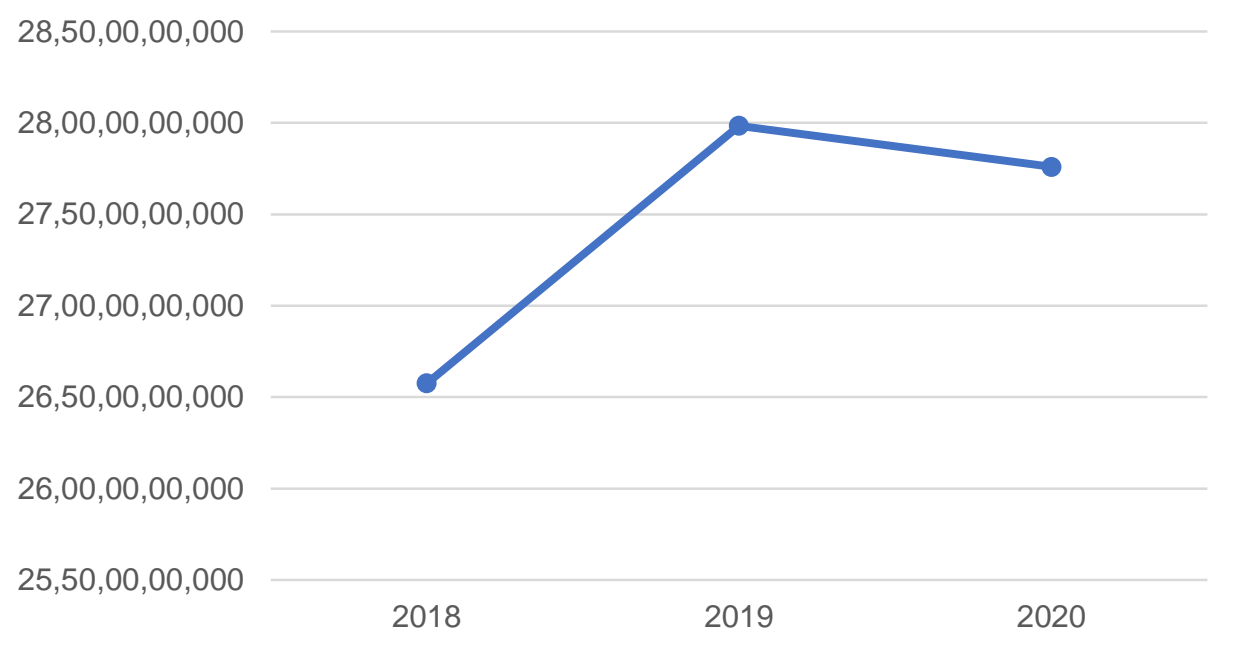

Figure 2 Changes in sales in the last three years[2]

\section{SWOT ANALYSIS}

\subsection{Advantage}

\subsubsection{Well-known by individuals}

Because of its special history with Germany, Tsingtao Beer International Festival is famous not only in China, but all over the world as well. The similar flavor to German beer and extensive propaganda, this festival attracts plenty of tourists from all over the world especially Germany. Also, as the biggest beer brand, Tsingtao Beer has become a symbol of Tsingtao. Developing unique foods and beverages are required to draw tourists from other country and regions [3]. As a local brand, Tsingtao Beer International Festival is charming enough to attract foreigners.

\subsubsection{Support of local government}

Tsingtao Beer International Festival is held by the government now, its place can be provided by the local government. Since 2018, Tsingtao Beer International Festival has been held jointly by five places which enlarge the accommodation of the tourists. Tsingtao Beer International Festival prepares to go out of Tsingtao in 2021 and host the first beer festival in Heze, Shandong province.

\subsection{Disadvantage}

As one of the main packaging of beer, the price of tin has been in a high position, because the supply elasticity of tin is small makes the supply slightly lag, leading to the overall strong shock of Shanghai tin.
Shanghai tin futures index rose from 120650 in March 2020 to 226230 in July 2021. With the improvement of price level and the increase of supply, the economic side effects of the post-epidemic era have emerged. The fragile employment income, the increase of low interest rate risk and the intensified game of big powers will bring resistance to economic recovery. As a result, the price of the tin will remain at a higher position about $13.8 \sim 16.0$ million yuan【4】.So, the cost of canned products of Tsingtao Beer will increase and decreasing the profit of Tsingtao Beer.

Also, a lack of product category might lead Tsingtao Beer to face trouble. For example, because of cultural reasons, liquor in China's alcoholic beverage market also accounted for a considerable proportion. Cocktail drinks such as Rio are also popular among young people. A single beer product will decline in certain market share with the emergence of new tastes of alcoholic beverages. Although Tsingtao Beer Company has launched a new soda drink, the market share of these sodas is most of the Yuan qi Forest and other emerging brands.

\subsection{Opportunity}

The continuous development of the logistics industry has enabled Tsingtao Beer to be sold further including overseas. As in Figure 3, sales volume of the beer export gradually increased in the past years. The increase in beer exports means a higher reputation of Chinese beer in other countries, but it also brings broader world markets. 


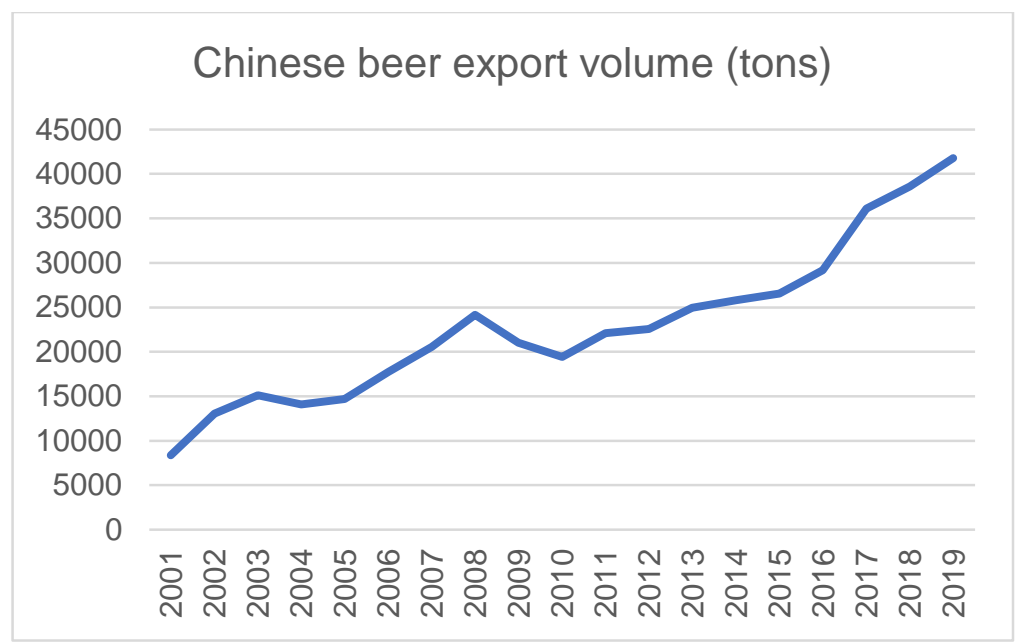

Figure 3 Chinese beer export volume (tons)【5】

With the continuous development of logistics, in the domestic market, the gross interest rate of Tsingtao Beer in various regions of China has increased compared with last year. The sales of Qingdao beer in various regions of China in 2020 are shown in Table 1. Shandong, which is the main producing area of Qingdao beer, has the highest gross profit rate and the highest operating income. In East China, the gross profit rate increased most than last year.

Table 1 Regional sales of Qingdao Beer【2】

\begin{tabular}{|c|c|c|c|c|c|c|}
\hline District & $\begin{array}{l}\text { Operating } \\
\text { Income }\end{array}$ & $\begin{array}{l}\text { Operating } \\
\text { Cost }\end{array}$ & $\begin{array}{l}\text { Gross } \\
\text { Rate }\end{array}$ & $\begin{array}{l}\text { Operating income } \\
\text { increases or } \\
\text { decreases over the } \\
\text { last year }(\%)\end{array}$ & $\begin{array}{lr}\text { Operating } & \text { cost } \\
\text { increases } & \text { or } \\
\text { decreases } & \text { over } \\
\text { the last year }(\%)\end{array}$ & $\begin{array}{l}\text { Gross interest } \\
\text { rate lower } \\
\text { than last year } \\
(\%)\end{array}$ \\
\hline Shandong Province & $18,026,420$ & $11,681,623$ & 35.2 & -1.49 & -2.39 & $0.60 \%$ \\
\hline North Part of China & $6,489,668$ & $4,225,025$ & 34.9 & 3.53 & 1.41 & $1.36 \%$ \\
\hline South Part of China & $3,268,886$ & $2,120,732$ & 35.12 & -4.73 & -7.25 & $1.75 \%$ \\
\hline East part of China & $2,802,879$ & $1,937,267$ & 30.88 & 1.58 & -5.9 & $5.49 \%$ \\
\hline $\begin{array}{l}\text { Southeast Part of } \\
\text { China }\end{array}$ & 822,715 & 579,435 & 29.57 & -0.06 & -7.18 & $5.40 \%$ \\
\hline
\end{tabular}

\subsection{Threat}

Because of the epidemic, China has constrained tourists from other countries. China has fewer inbound flights, strict quarantine of foreigners and higher ticket prices, reducing the number of visitors to Tsingtao Beer International Festival. At the same time, during the spring festival, most of the residents choose to stay at home instead of going out to dinner harshly decrease the consumption of the beer.

Other brands of beer in China are still developing. On July 1, 2018, the Chinese government cut tariffs on beer from 35 to 5 percent, so foreign brands such as Baiwei and Xili expanded their sales in China and expanded their factories. In 2018, the market share of Huarun beer was $25.1 \%$, ranking the first and the first sales in China. In the advanced beer market, Baiwei Beer accounted for $30 \%$ in 2018, while Tsingtao Beer accounted for only $10 \%$. Although Tsingtao Beer has a higher reputation and is well-known in China, Tsingtao Beer is still not the first in the industry in the beer market [6].

\section{PEST ANALYSIS}

PEST analysis in this paper is used to evaluate the current and future market of Tsingtao beer in the fields of politics, economy, society and technology.

\subsection{Political}

Tsingtao Beer was strongly supported by Chinese government which come up with plenty of policies to encourage the development of craft beer. Shandong provincial government proposed to propagate Tsingtao Beer International Festival, striving for more national platforms, support cities to create regional open brands, focusing on building Tsingtao International Beer City.

\subsection{Economy}

As a tourist city, the development of Tsingtao Beer International Festival has promoted the development of Tsingtao ' $\mathrm{s}$ tourism industry and led to economic benefits. During the annual Beer Festival, the hotel and ticket prices towards Tsingtao increased rapidly. However, in large-scale festivals, there will be a large 
population influx in a short time, Tsingtao Beer International Festival is held in densely populated areas, which is easy to cause ecological damage and environmental pollution[7]. During the outbreak in 2020, due to the increased risk of infection, the number of visitors to Tsingtao Beer International Festival decreased significantly, bringing economic decrease to Tsingtao [8].

\subsection{Society}

It is known as a well-known brand in China, Tsingtao Beer's influence throughout the country. Table I shows that, Tsingtao Beer set up sales channels and sales positions all over China, as well as the annual number of participants in Tsingtao Beer International Festival, proved the influence of Tsingtao Beer and Chinese people for Tsingtao Beer 's love, so Tsingtao Beer has a certain influence on society.

\subsection{Technology}

Tsingtao Beer in the future process can invest more money to do product development, such as the non-Saccharomyces yeasts discovered by Laura Canonico could be a suitable strategy to manage a premium craft beer fermentation with a promising sensory profile with the future prospects to introduce in the market an improved product [6].

\section{BUSINESS STRATEGIES TSINGTAO BEER COMPANY HAS APPLIED}

Facing those difficulties, Tsingtao Beer company started to find their own solutions so that they can reverse the deficit in January and February.

\subsection{Donating anti-epidemic supplies to communities}

Tsingtao Beer donated 10-million-yuan cash and 2 million yuan of anti-epidemic supplies to Tsingtao Red Cross for epidemic prevention and control. Tsingtao Beer donated such a large number of anti-epidemic supplies to build a good corporate image and reputation. If Qingdao beer can invest more in the beer formula upgrade and taste change, perhaps can obtain greater benefits. After that, citizens are more likely to buy their products.

\subsection{Starting online selling}

Since citizens cannot go out to dinner or shopping, Tsingtao Beer set up a new sales team to carry out community, WeChat group and other new marketing methods to ensure the smooth marketing channels. On account of the convenient express companies and collaboration with Meituan takeout, Ele.me takeout platforms, Tsingtao Beer started to sell beers online and deliver to citizens' homes. In March, Tsingtao Beer promotes cooperation with Tianmao, Jingdong, Suning and other e-commerce platforms, using the network platform to expand marketing channels, selling offline inventory online, and finally achieved good results. Tsingtao Beer for such a special period, launched a contactless mode, intelligent distribution according to geographical location, shorten the distribution time and reduce the risk of infection.

\subsection{Change its own selling strategy}

During the epidemic period, in order to promote sales Tsingtao Beer, use the strategy of giving part of the profit to the salesman. Everyone can generate their own QR code to become a salesman to invite others, when others customers buying Tsingtao Beer can get a return, this promotion greatly increasing the sales of Tsingtao Beer.

These three main sales strategies contribute to the operating income in 2020. So, compared with other loss-making enterprises during the epidemic period, the profit operating income of Tsingtao Beer during the epidemic period was basically the same as that of previous years, which was a good outcome. Therefore, in the stock market, investors buy more stock of Tsingtao Beer, the stock price of Tsingtao Beer rising from 51.11 yuan (2020.1.2) to 99.66 yuan (2020.12.30) increased about $95 \%$.

\section{CONCLUSION}

Its new business strategies can be learnt by worldwide beverage companies so that they can overcome the difficulties during the epidemic. Faced with the problem of market share being squeezed, Tsingtao Beer can take brand awareness as the advantage, increase investment in propaganda, through the media and advertising to vigorously promote, increase consumer brand loyalty and enhance brand influence, leaving a better impression on consumers to increase market share.

In 2021, due to the control of the epidemic situation in China, the number of people travelling to Qingdao to participate in the Tsingtao Beer International Festival will increase, and more tourists will increase the consumption of beer. At the same time, the increase in venues will lead to an increase in costs and operating income. Tsingtao Beer International Festival should learn from the greatest beer festival, the Oktoberfest [9]. From the perspective of Robert J. Harrington, the physical environment includes tangible elements and more general aspects of the atmosphere. Satisfiers identified in this area of the Oktoberfest experience include the atmosphere in the tent, the quality of live music, the number of people in the tent, and the physical 
location of the tent. Food quality, beverage quality and staff quality were also shown to impact satisfaction in the Oktoberfest setting. If the Tsingtao Beer festival concentration on the element above, it will lead to better success.

\section{ACKNOWLEDGMENTS}

Throughout the writing of this dissertation, I have received a great deal of support and assistance.

I would first like to acknowledge Professor, Steve Coggeshall, from University of Southern California for inspiring my interest in the business analysis, opened my mind and also acquire more knowledge of business.

I would also like to thank to my teaching assistant and advisor, Yuhui Li and Min Han. With their helped of guidance and taught me the methodology of analysis, I can complete the article.

In addition, I would like to thank my school, Xi'an University of Finance and Economics. After three years' study of accounting, I can easily extract information of the annual report and use my subject knowledge to find out the solutions and figure out the outcome.

\section{REFERENCES}

[1] Yang Yang, Hongru Zhang, Xiang Chen, Coronavirus pandemic and tourism: Dynamic stochastic general equilibrium modeling of infectious disease outbreak, Annals of Tourism Research, Volume 83, 2020, 102913, ISSN 0160-7383, https://doi.org/10.1016/j.annals.2020.102913.

[2] Data from Qingdao Beer Annual Report (2020) (2019) (2018) Laura Canonico, Emanuele Zannini, Maurizio Ciani, Francesca Comitini, Assessment of non-conventional yeasts with potential probiotic for protein-fortified craft beer production, LWT, Volume 145, 2021, 111361, ISSN 0023-6438, https://doi.org/10.1016/j.lwt.2021.111361.

[3] Kanghwa Choi, Hee Jay Kang, Changhee Kim, Evaluating the efficiency of Korean festival tourism and its determinants on efficiency change: Parametric and non-parametric approaches, Tourism Management, Volume 86, 2021, 104348, ISSN 0261-5177, https://doi.org/10.1016/j.tourman.2021.104348.

[4] Li Chunyan. Tin - Supply and demand rebound, but the overall economic recovery momentum is insufficient, Shanghai Tin may be high shock [ J ]. Yunnan Metallurgy, 2020,49 ( 06 ) : 12.

[5] Data come from Wind database (2018)
[6] Data from China National Data Network, https://data.stats.gov.cn/easyquery.htm?cn=C01\&z $\mathrm{b}=\mathrm{A} 060601 \& \mathrm{sj}=2019$

[7] Yuan Rong. Research on the promotion of Tsingdao Beer Festival to Qingdao's tourism economy [J]. Holiday tourism, 2018 (08) : $94-95$.

[8] Gokhan Karabulut, Mehmet Huseyin Bilgin, Ender Demir, Asli Cansin Doker, How pandemics affect tourism: International evidence, Annals of Tourism Research, Volume 84, 2020, 102991, ISSN 0160-7383, https://doi.org/10.1016/j.annals.2020.102991.

[9] Robert J. Harrington, Burkhard von Freyberg, Michael C. Ottenbacher, Laura Schmidt,The different effects of dis-satisfier, satisfier and delighter attributes: Implications for Oktoberfest and beer festivals,

[10]Tourism Management Perspectives, Volume 24, 2017, Pages 166-176, ISSN 2211-9736, https://doi.org/10.1016/j.tmp.2017.09.003. 